Article

\title{
The Possible Role of Penning Ionization Processes in Planetary Atmospheres
}

\section{Stefano Falcinelli ${ }^{1,2, *}$, Fernando Pirani $^{3}$ and Franco Vecchiocattivi ${ }^{2}$}

1 Department of Chemistry, Stanford University, Stanford, CA 94305, USA

2 Department of Civil and Environmental Engineering, University of Perugia, Via G. Duranti 93, Perugia 06125, Italy; E-Mail: franco.vecchiocattivi@unipg.it

3 Department of Chemistry, Biology and Biotechnologies, University of Perugia, Via Elce di Sotto 8, Perugia 06123, Italy; E-Mail: fernando.pirani@unipg.it

* Author to whom correspondence should be addressed; E-Mail: stefano.falcinelli@unipg.it; Tel.: +39-075-585-3856; Fax: +39-075-585-3864.

Academic Editor: Armin Sorooshian

Received: 9 January 2015 / Accepted: 27 February 2015 / Published: 11 March 2015

\begin{abstract}
In this paper we suggest Penning ionization as an important route of formation for ionic species in upper planetary atmospheres. Our goal is to provide relevant tools to researchers working on kinetic models of atmospheric interest, in order to include Penning ionizations in their calculations as fast processes promoting reactions that cannot be neglected. Ions are extremely important for the transmission of radio and satellite signals, and they govern the chemistry of planetary ionospheres. Molecular ions have also been detected in comet tails. In this paper recent experimental results concerning production of simple ionic species of atmospheric interest are presented and discussed. Such results concern the formation of free ions in collisional ionization of $\mathrm{H}_{2} \mathrm{O}, \mathrm{H}_{2} \mathrm{~S}$, and $\mathrm{NH}_{3}$ induced by highly excited species (Penning ionization) as metastable noble gas atoms. The effect of Penning ionization still has not been considered in the modeling of terrestrial and extraterrestrial objects so far, even, though metastable helium is formed by radiative recombination of $\mathrm{He}^{+}$ions with electrons. Because helium is the second most abundant element of the universe, Penning ionization of atomic or molecular species by $\operatorname{He}^{*}\left(2^{3} \mathrm{~S}_{1}\right)$ is plausibly an active route of ionization in relatively dense environments exposed to cosmic rays.
\end{abstract}


Keywords: Penning ionization; hydrogenated molecules; metastable rare gas atoms; planetary atmospheres; mass spectrometry; electron spectroscopy; crossed molecular beams

\section{Introduction}

In general, atomic or molecular species can be ionized by using photons of sufficient energy: in this case we have photoionization processes. Alternately, it is possible to induce ionization via collision events involving energetic and excited particles, like energetic electrons and metastable atoms or molecules. In the latter case we have the so-called Penning ionization or chemi-ionization processes. As will be discussed in the next section, we are suggesting Penning ionization as an important route of formation for ionic species in the upper planetary atmospheres. The knowledge of cross sections, rate constants, and the stereodynamics driving such reactions should be useful to provide full basic physical chemical data needed as input for calculations that model the atmospheric chemistry of Earth and other planets of the solar system, like Mars and Mercury.

Free ionic species are extremely important for the transmission of radio and satellite signals. In fact, due to the presence of high amounts of ions and free electrons, the ionosphere plays an important role in the transmission of electromagnetic waves (especially HF radio and satellite waves). Indeed, the incidence of a HF radio wave on an ionized layer can produce total reflection under appropriate conditions, contrary to what happens on atmosphere without ionization events (whose refractive index exhibits variations generally too small to produce the total reflection of a wave) [1-3]. In addition, experimental observations demonstrate a significant improvement in the propagation of these waves after thunderstorms, especially concerning high HF bands (21-24-28 MHz) [4]. This effect is not yet fully understood and is correlated to the presence of electrical discharges in the Earth's atmosphere (statistically, from thunderstorms about 100 electrical discharges occur every second) with a huge amount of energy able to ionize and excite atomic and molecular species. For more than 20 years, studies have clearly shown that, when atoms and simple molecules (for example, $\mathrm{H}, \mathrm{O}$, rare gas atoms, and $\mathrm{N}_{2}$ molecules) are subjected to electrical discharges, they produce a large amount of species in highly excited electronic metastable states (see Table 1). These metastable atoms or molecules can induce Penning ionization by collisions with neutral atomic or molecular targets with high efficiency [5-7]. In particular, the presence in our terrestrial atmosphere of argon (the third component of air at $0.93 \%$ ), and of a minor amount of neon and helium (with concentrations of about 18 and $5 \mathrm{ppm}$, respectively), makes highly probable, in these circumstances, the production of ionized species by Penning ionization induced by these rare gas metastable atoms. It has to be noted that these processes are still not fully considered in kinetic models used to describe the physical chemistry of such environments. We are confident that our research is able to clarify the possible role played by Penning ionization processes in Earth's atmosphere, contributing to the attempt to explain some unclear phenomena, for example the "sprites" formation, i.e., phenomena similar to lightning, showing a big influence on radio wave propagation. They are formed in the stratosphere (between 10 and $100 \mathrm{~km}$ ) through electrical discharges of the duration of a few tenths of a second, which are created by the electrical potential difference between the clouds and the upper atmosphere even in the absence of thunderstorms [8]. Because these phenomena 
happen in certain meteorological conditions and in the presence of electrical discharges, we suggest that they could be related to the formation in the atmosphere of a strong local increase in the ionic concentration due to Penning ionization processes induced by argon, neon, and helium metastable atoms that would facilitate the transmission of the radio waves by reflection.

Table 1. Some characteristics of metastable atomic and molecular species [5].

\begin{tabular}{ccc}
\hline Excited Species & Excitation Energy $(\mathbf{e V})$ & Lifetime (s) \\
\hline $\mathrm{H}^{*}\left(2 \mathrm{~s}^{2} \mathrm{~S}_{1 / 2}\right)$ & 10.1988 & 0.14 \\
$\mathrm{He}^{*}\left(2^{1} \mathrm{~S}_{0}\right)$ & 20.6158 & 0.0196 \\
$\mathrm{He}^{*}\left(2^{3} \mathrm{~S}_{1}\right)$ & 19.8196 & 9000 \\
$\mathrm{Ne}^{*}\left({ }^{3} \mathrm{P}_{0}\right)$ & 16.7154 & 430 \\
$\mathrm{Ne}^{*}\left({ }^{3} \mathrm{P}_{2}\right)$ & 16.6191 & 24.4 \\
$\mathrm{Ar}^{*}\left({ }^{3} \mathrm{P}_{0}\right)$ & 11.7232 & 44.9 \\
$\mathrm{Ar}^{*}\left({ }^{3} \mathrm{P}_{2}\right)$ & 11.5484 & 55.9 \\
$\mathrm{Kr}^{*}\left({ }^{3} \mathrm{P}_{0}\right)$ & 10.5624 & 0.49 \\
$\mathrm{Kr}^{*}\left({ }^{3} \mathrm{P}_{2}\right)$ & 9.9152 & 85.1 \\
$\mathrm{Xe}^{*}\left({ }^{3} \mathrm{P}_{0}\right)$ & 9.4472 & 0.078 \\
$\mathrm{Xe}^{*}\left({ }^{3} \mathrm{P}_{2}\right)$ & 8.3153 & 150 \\
$\mathrm{O}^{*}\left(2 \mathrm{p}^{3} 3 \mathrm{~s}^{5} \mathrm{~S}_{2}\right)$ & 9.146 & $1.85 \times 10^{-4}$ \\
$\mathrm{H}_{2}{ }^{*}\left(\mathrm{c}^{3} \Pi_{\mathrm{u}}{ }^{-}\right)$ & 11.764 & $1.02 \times 10^{-3}$ \\
$\mathrm{~N}_{2}{ }^{*}\left(\mathrm{~A}^{3} \Sigma_{\mathrm{u}}{ }^{+}\right)$ & 6.169 & 1.9 \\
$\mathrm{~N}_{2}{ }^{*}\left(\mathrm{~A}^{1} \Pi_{\mathrm{g}}\right)$ & 8.549 & $1.20 \times 10^{-4}$ \\
$\mathrm{~N}_{2}{ }^{*}\left(\mathrm{E}^{3} \Sigma_{\mathrm{g}}^{+}\right)$ & 11.875 & $1.90 \times 10^{-4}$ \\
$\mathrm{CO}^{*}\left(\mathrm{a}^{3} \Pi\right)$ & 6.010 & $\geq 3 \times 10^{-3}$ \\
\hline
\end{tabular}

The presence of ions in the upper terrestrial atmosphere was soon recognized after the experiment of Marconi in 1901, who succeeded in transmitting radio waves from the United Kingdom to Canada. Later, the ion $\mathrm{CH}^{+}$was detected in space, practically at the same time as the detection of the first neutral molecules, $\mathrm{CH}$ and $\mathrm{CN}$ [9]. Ions are extremely important in the upper atmosphere of planets, where they govern the chemistry of ionospheres. Furthermore, molecular ions have also been detected in comet tails [9]. In planetary ionospheres and in space, ions are formed in various ways, the importance of which depends on the specific conditions of the considered environment. The interaction of neutral molecules with cosmic rays, UV photons, X-rays, and other phenomena such as shock waves are all relevant processes for their production [10]. In particular, the absorption of UV photons with an energy content higher than the ionization potential of the absorbing species can induce photoionization (for most species, extreme-UV or far-UV photons are necessary). Cosmic rays are also important since they are ubiquitous and carry a large energy content (up to $100 \mathrm{GeV}$ ).

The detailed laboratory characterization of relevant elementary processes and their relative role, leading to the formation of atomic and molecular ions, is therefore of crucial importance. In this paper recent experimental results concerning production and characterization via Penning ionization of simple ionic species of atmospheric interest are presented. The discussed data concern the formation of free ions in collisional ionization of $\mathrm{H}_{2} \mathrm{O}, \mathrm{H}_{2} \mathrm{~S}$, and $\mathrm{NH}_{3}$ induced by highly excited species. As mentioned above, the effect of Penning ionization has not yet been fully considered in the modeling of terrestrial and extraterrestrial objects, even though metastable helium is known to be formed by photoelectron impact 
and radiative recombination of $\mathrm{He}^{+}$ions with electrons [11,12]. In fact, it is well-known that the $1083 \mathrm{~nm}$ twilight airglow arises from resonant scattering of solar photons by metastable $\operatorname{He}^{*}\left(2^{3} \mathrm{~S}\right)$ atoms in the upper thermosphere and exosphere (see, for instance [13], and references therein). Having a radiative lifetime of $2.5 \mathrm{~h}$ and an energy content of $19.82 \mathrm{eV}$, Penning ionization of molecules by $\operatorname{He}^{*}\left(2^{3} \mathrm{~S}_{1}\right)$ (helium is the second most abundant element of the universe) is plausibly an active route of ionization in relatively dense environments exposed to cosmic rays for two main reasons: (i) recent studies have shown that the $\operatorname{He}^{*}\left(2^{3} \mathrm{~S}\right)$ density profiles in the Earth's atmosphere reach their maximum values at about $600 \mathrm{~km}$ altitude, changing with the investigated solar zenith angle, and ranging between 0.6 and 1.1 atoms $/ \mathrm{cm}^{3}$ [13]; and (ii) with respect to ionization by VUV photons and cosmic rays, Penning ionization processes are characterized by much higher cross-sections [14,15]. Moreover, concerning the role of $\mathrm{He}^{*}\left(2^{3} \mathrm{~S}\right)$ metastable atoms in the interstellar medium, in a recent paper Indriolo et al. derived new equations for the steady state abundance of $\mathrm{He}^{*}$ using its $1083 \mathrm{~nm}$ absorption line data observed through the diffuse clouds toward HD 183143 [11]. By their analysis the authors inferred an upper limit for the cosmic-ray ionization rate of helium of $1.2 \times 10^{-15} \mathrm{~s}^{-1}$, which is an important route of $\operatorname{He}^{*}\left(2^{3} \mathrm{~S}\right)$ formation via cosmic-ray ionization of helium atoms, followed by radiative recombination of the ions with electrons, as mentioned before. This ionization rate value is higher than those related to the ionization of interstellar hydrogen (various models have predicted ionization rates from $10^{-18} \mathrm{~s}^{-1}$ up to $10^{-15} \mathrm{~s}^{-1}$ ) in the diffuse interstellar medium, or in comparison with the ionization of other molecules such as HD and $\mathrm{OH}$ having estimated ionization rates of the order of $10^{-17} \mathrm{~s}^{-1}$ [11]. These data allow us to highlight the importance of the chemistry associated with interstellar metastable helium, and the possible use of $\mathrm{He}^{*}\left(2^{3} \mathrm{~S}\right)$ as a widely applicable probe of the cosmic-ray ionization rates, as suggested by Indriolo et al. [11].

Penning ionization is an autoionizing process involving the collision complex between an excited species and an atomic or molecular target. The collision will yield various ion products when the ionization potential of the target particle is lower than the excitation energy of the primary metastable species. Very common species able to induce Penning ionization are the rare gas atoms excited to their first electronic level, which is a metastable state (their lifetime is long enough to allow them to survive at least several seconds); this makes them able to ionize upon collision many atomic and molecular targets (they are characterized by a high excitation energy which ranges from $8.315 \mathrm{eV}$, in the case of $\mathrm{Xe}^{*}\left({ }^{3} \mathrm{P}_{2}\right)$, up to $20.616 \mathrm{eV}$, in the case of $\left.\mathrm{He}^{*}\left({ }^{1} \mathrm{~S}_{0}\right)\right)$. These ionization reactions were widely studied starting in 1927 by F.M. Penning [16]. They can be schematized as follows:

$$
\mathrm{Rg}^{*}+\mathrm{M} \rightarrow[\mathrm{Rg} . . \mathrm{M}]^{*} \rightarrow[\operatorname{Rg} \ldots \mathrm{M}]^{+}+\mathrm{e}^{-} \rightarrow \text { ion products }
$$

where $\mathrm{Rg}$ is a rare gas atom, $\mathrm{M}$ is an atomic or molecular target, $[\mathrm{Rg} . . \mathrm{M}]^{*}$ represents the intermediate autoionizing collisional complex, and $[\mathrm{Rg} . . \mathrm{M}]^{+}$the intermediate transient ionic species formed by the electron ejection. This is the most efficient way for the collisional system [Rg...M $]^{*}$ to lose its excitation energy, since the autoionization time is usually shorter than the characteristic molecular collision time at thermal energies $\left(\sim 10^{-12} \mathrm{~s}\right)$. Then, various final product ions can be formed depending on the characteristics of the involved potential energy surfaces. Some specific features make these processes very interesting from a fundamental point of view. In fact, at high interatomic separation the metastable rare gas atoms behave as alkaline metals because of their weakly bound external electron, whereas at shorter distances the role of their "open shell" core becomes prominent, looking like halogen atoms. 
Therefore, their phenomenological behavior when interacting with hydrogenated molecules $\left(\mathrm{H}_{2} \mathrm{O}, \mathrm{H}_{2} \mathrm{~S}\right.$, $\mathrm{NH}_{3}$ ) is very interesting for fundamental and applied science, as shown by the many discussions in the literature about the role of hydrogen and halogen bonds [17].

However, many applications of collisional autoionization to important fields, like radiation chemistry, plasma physics, and chemistry, and the development of laser sources, are also possible. In some cases, this technique is also used to induce gentle ionization of complex molecules.

In general, the role of metastable rare gas atoms in Earth's atmospheric reactions is of interest for a number of reasons: (i) the quantity of rare gas atoms in the atmosphere is not negligible (argon is the third component of the air, after nitrogen and oxygen molecules: $0.934 \% \pm 0.001 \%$ by volume compared to $0.033 \% \pm 0.001 \%$ by volume of $\mathrm{CO}_{2}$ molecules); (ii) as mentioned in the previous section, recent studies have shown that the upper atmosphere of our planet is relatively rich in $\mathrm{He}^{*}\left(2^{2} \mathrm{~S}_{1}\right)$ metastable atoms $[18,19]$; and (iii) rate constants for ionization processes induced by metastable rare gas atoms are generally larger than those of common bimolecular chemical reactions of atmospheric interest. For example, the rate constants for Penning ionization processes are of the same order of magnitude as gas phase bimolecular reactions of $\mathrm{O}\left({ }^{1} \mathrm{D}\right), \mathrm{Cl}\left({ }^{2} \mathrm{P}\right)$, or $\mathrm{Br}\left({ }^{2} \mathrm{P}\right)$, which are known to be relevant in the modeling of atmospheric chemistry, whereas other important reactions (as for example those involving $\mathrm{Br}+\mathrm{O}_{3}$, $\mathrm{O}+\mathrm{HOCl}$, and $\mathrm{OH}+\mathrm{HOCl}$ ), exhibit rate constants that are at least one order of magnitude smaller [20].

Considering the planetary atmospheric compositions, we can suppose that rare gas atoms are involved in several atmospheric phenomena not only on Earth, but also on other planets of the solar system, like Mars and Mercury. In fact, argon is the third component of the Martian atmosphere at $1.6 \%$, while helium is a relatively abundant species (about 6\%) in the low density atmosphere of Mercury. As mentioned in the previous section, a basic step in the chemical evolution of planetary atmospheres and interstellar clouds (where $89 \%$ of atoms are hydrogen and $9 \%$ are helium) is the interaction of atoms and molecules with electromagnetic waves ( $\gamma$ and X rays, UV light) and cosmic rays. Therefore, $\mathrm{He}^{*}$ and $\mathrm{Ar}^{*}$ formation by collisional excitation with energetic target particles (like electrons, protons, or alpha particles) and the possible subsequent Penning ionization reactions could be of importance in these environments. In particular, considering the tenuous exosphere of Mercury, it is interesting to note that in 2008 the NASA spacecraft MESSENGER discovered surprisingly large amounts of water and several atomic and molecular ionic species including $\mathrm{O}^{+}, \mathrm{OH}^{-}, \mathrm{H}_{2} \mathrm{O}^{+}$, and $\mathrm{H}_{2} \mathrm{~S}^{+}$(NASA and the MESSENGER team will issue periodic news releases and status reports on mission activities and make them available online). Taking into account the suggested polar deposits of water ice in this planet, McClintock and Lankton in 2007 have suggested impact vaporization mechanisms [21]. We argue that in these parts of the planetary surface, the presence of $\mathrm{He}^{*}$ and its collisions can cause subsequent ion formation. In this respect, the study of the Penning ionization of water and hydrogen sulfide by metastable rare gas atoms $\left(\mathrm{He}^{*}\right.$ and $\mathrm{Ne}^{*}$, see Section 3), producing $\mathrm{H}_{2} \mathrm{O}^{+}, \mathrm{OH}^{+}, \mathrm{O}^{+}$, and $\mathrm{H}_{2} \mathrm{~S}^{+}$, respectively, could help in explaining the possible routes of formation for these ionic species in Mercury's exosphere. The importance of these processes and, in particular, of Penning ionization phenomena of hydrogenated molecules by $\mathrm{He}^{*}$ and $\mathrm{Ne}^{*}$ metastable atoms has been widely discussed in [22-24], to which we refer for an overview of the experimental and theoretical works performed since the 1970s by several research groups, starting with the pioneering works by Čermák and Yencha [25] and by Brion and Yee [26].

We have recently studied the ionization of water molecules by Penning ionization coupled with both Mass Spectrometry (MS) and Electron Spectroscopy (PIES) techniques [22-24]. The analysis of the 
obtained results suggests the selective role of a quite pronounced anisotropic attraction that controls the stereodynamics in the entrance channels of the analyzed systems. In the case of $\mathrm{He}^{*}$ and $\mathrm{Ne}^{*}-\mathrm{H}_{2} \mathrm{O}$ autoionizing collisions, we were able to confirm the presence of a strong anisotropic interaction, after previous experimental and theoretical evidences by Ohno et al. [27], Haug et al. [28], Bentley [29], and Ishida [30], respectively. In particular, we rationalized our experimental findings, taking into account the critical balancing between molecular orientation effects in the intermolecular interaction field and the ionization probability. In analyzing our PIES spectra, a novel semiclassical method was proposed: (i) it assumes ionization events as mostly occurring in the vicinities of the collision turning points (where the main part of the collision time is accumulated because the relative velocity tends to zero); and (ii) the potential energy driving the system in the relevant configurations of the entrance and exit channels, employed in the spectra simulation, has been represented by the use of a semiempirical method and given a proper analytical form [24]. This procedure was able to clearly point out how different approaches between the metastable atom and water molecules promote the formation of ions in different electronic states. In particular, it provides the angular acceptance cones where the stereo-selectivity of the processes leading to the specific formation of each one of the two energetically possible electronic states of $\mathrm{H}_{2} \mathrm{O}^{+}$final product ions [24] (the $\mathrm{X}^{2} \mathrm{~B}_{1}$ ground state and the first $\mathrm{A}^{2} \mathrm{~A}_{1}$ excited ones) mainly manifests.

In the present work we analyze our recent PIES spectra, collected in $\mathrm{He}^{*}, \mathrm{Ne}^{*}-\mathrm{H}_{2} \mathrm{~S}$, and $\mathrm{NH}_{3}$ collisions, by using the same procedure already applied to water molecules, in order to compare the three sets of data, obtained under the same experimental conditions (see next Section), and to identify relevant differences in the stereodynamics of Penning ionization of the three hydrogenated molecules. In particular, our recent results recorded in $\mathrm{He}^{*}$ and $\mathrm{Ne}^{*}-\mathrm{H}_{2} \mathrm{~S}$ collisional experiments clearly suggest again the formation of molecular ions both in the ground and in the first excited electronic state. They are also indicating similar anisotropic behavior for the potential energy surface describing the $\mathrm{Rg}^{*}-\mathrm{H}_{2} \mathrm{~S}$ incoming channel with an attractive component less "effective" with respect to $\mathrm{Rg}^{*}-\mathrm{H}_{2} \mathrm{O}$ (see Section 3). In the case of ammonia, anisotropic behavior is still present, with a strong attractive interaction between $\mathrm{Rg}^{*}-\mathrm{NH}_{3}$ collisional partners (where $\mathrm{Rg}=\mathrm{He}, \mathrm{Ne}$ ), as in the $\mathrm{Rg}^{*}-\mathrm{H}_{2} \mathrm{O}$ case (see Section 3).

\section{Experimental Techniques}

The experimental setup, consisting of a crossed molecular beam apparatus (three vacuum chambers which are differentially pumped at a pressure of about $10^{-7} \mathrm{mbar}$ ) is schematically sketched in Figure 1 and described in detail in some previous works [31-33].

In such an apparatus a molecular beam of excited atoms, mostly metastable rare gas atoms, is crossing at right angles a second beam of molecules (to be ionized). Electrons produced in photo- and/or chemi-ionization reactions are extracted and analyzed by an appropriate electron energy selector, while product ions are sent into a quadrupole mass spectrometer (located below the beam's crossing volume), where they are mass analyzed and detected. A powerful improvement of our apparatus could be realized by introducing the coincidence detection technique for the related electrons and ions coming out of the same autoionizing $[\operatorname{Rg} \ldots \mathrm{M}]^{*}$ collisional complex (see Equation (1)). 


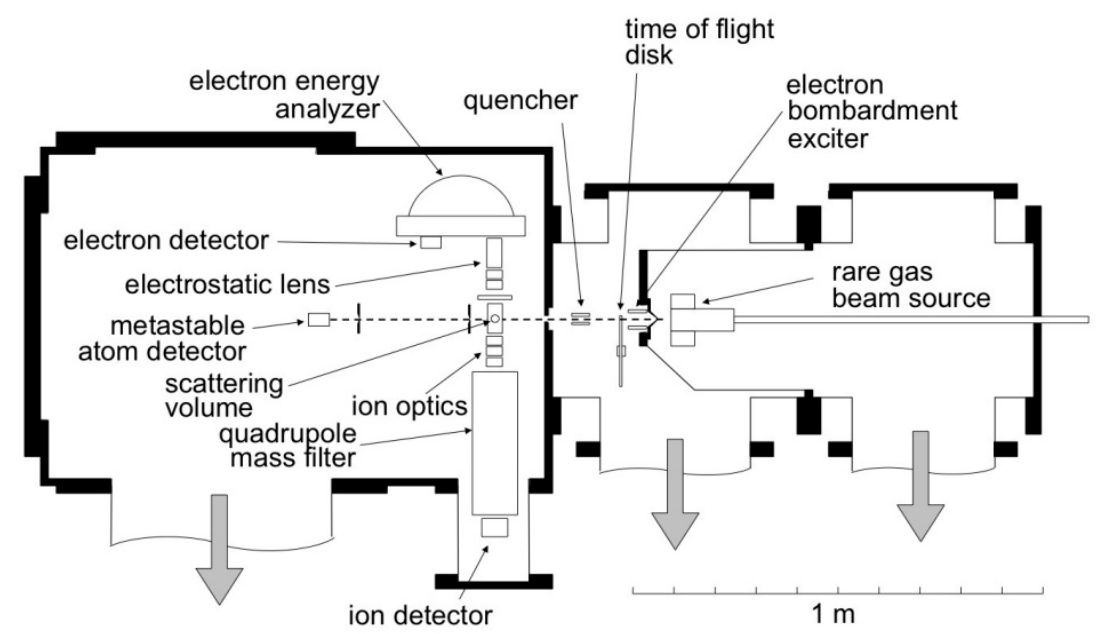

Figure 1. The crossed molecular beam apparatus used in Penning ionization studies.

The metastable rare gas beam, produced by electron bombardment or by a microwave discharge beam source, crosses at a right angle an effusive beam of $\mathrm{H}_{2} \mathrm{O}, \mathrm{H}_{2} \mathrm{~S}$, or $\mathrm{NH}_{3}$ target molecules. The kinetic energy of emitted electrons is recorded by the use of a hemispheric electrostatic analyzer, which is located above the crossing beam volume. In such a way we can perform, in the same experimental conditions, both photoionization (PES) and Penning Ionization Electron Spectroscopy (PIES) measurements. This can be easily achieved because the microwave discharge produces not only metastable atoms but also many $\mathrm{He}(\mathrm{I})$ and $\mathrm{Ne}(\mathrm{I})$ photons, having an energy comparable to that of metastable atoms. To calibrate the electron transmission efficiency and the electron energy scale, some $\mathrm{He}^{*}-\mathrm{H}_{2} \mathrm{O}, \mathrm{H}_{2} \mathrm{~S}, \mathrm{NH}_{3} \mathrm{PIES}$, and $\mathrm{Ne}(\mathrm{I})-\mathrm{H}_{2} \mathrm{O}, \mathrm{H}_{2} \mathrm{~S}, \mathrm{NH}_{3}$ PES spectra have been measured by exploiting the microwave discharge beam source: in the first case we use for the energy calibration the weak electron signal by $\mathrm{He}(\mathrm{I})$ photons of $21.22 \mathrm{eV}$, whereas in the latter case we record a PES spectrum, using the discharge source in pure neon producing a high intensity of $\mathrm{Ne}\left(\mathrm{I}_{\alpha, \beta}\right)$ photons [22,34], essentially of 16.84 and $16.66 \mathrm{eV}$, respectively, in a $\alpha: \beta$ ratio of about 5.3 , checked by photoelectron spectrometric measurements of $\mathrm{Kr}$ atoms $[35,36]$. By comparison of our measurements with the expected spectrum as obtained from the $\mathrm{He}(\mathrm{I})$ radiation by Kimura et al. [37], we calibrate the ionization energy scale. The resolution of our electron spectrometer is $\sim 45 \mathrm{meV}$ at a transmission energy of $3 \mathrm{eV}$, as determined by measuring the photoelectron spectra of $\mathrm{Ar}, \mathrm{O}_{2}$, and $\mathrm{N}_{2}$ by $\mathrm{He}(\mathrm{I})$ radiation with the procedure described in previous papers $[18,36]$. Spurious effects due to the geomagnetic field have been reduced to $\leq 20 \mathrm{mG}$ by a $\mu$-metal shielding. Finally, the metastable atom velocity can be analyzed by a time-of-flight technique: the beam is pulsed by a rotating slotted disk and the metastable atoms are counted, using a multiscaler, as a function of the delay time from the beam opening. The secondary molecular beam can be prepared in two ways: (i) by effusion of $\mathrm{H}_{2} \mathrm{O}, \mathrm{H}_{2} \mathrm{~S}$, or $\mathrm{NH}_{3}$ from a glass microcapillary array kept at room temperature, or (ii) by using a supersonic source whose nozzle temperature can be changed between 300 and $700 \mathrm{~K}$. The collision energy resolution is largely defined by the thermal spread of target molecules effusing from the microcapillary source (about 30\% full with a half-maximum (FWHM) velocity spread at the lowest relative velocity of $1100 \mathrm{~m} / \mathrm{s}$, and about $10 \%$ FWHM for the highest probed relative velocity of $1800 \mathrm{~m} / \mathrm{s}$ ), and in our experiment the average collision energy is about $55 \mathrm{meV}$. Absolute values of the total ionization cross-section for different species can be obtained by the 
measurement of relative ion intensities in the same conditions of metastable atom and target gas density in the crossing region. This allows the various systems to be put on a relative scale, which can be normalized by reference to a known cross-section such as, in the present case, the $\mathrm{Ne}^{*}-\mathrm{Ar}$ absolute total ionization cross-section by West et al. [38]. By analyzing the kinetic energy of the emitted electrons, we can perform a real spectroscopy of the collisional intermediate transient species for such a process, obtaining detailed information about the intermolecular potentials controlling the microscopic collision dynamics, the preferential geometries of approach between the collision partners, and the molecular orbitals involved in the autoionization event. On the other hand, looking at the product ions, we can determine the cross-sections for each open ionization channel, obtaining complementary information that enables us to achieve a complete understanding of the reaction dynamics for the system under study.

\section{Results and Discussion}

In this section recent experimental results of relevance for the characterization of simple ionic species of atmospheric interest, produced by Penning ionization of hydrogenated molecules $\left(\mathrm{H}_{2} \mathrm{O}, \mathrm{H}_{2} \mathrm{~S}\right.$, and $\mathrm{NH}_{3}$ ) with $\mathrm{He}^{*}$ and $\mathrm{Ne}^{*}$ metastable atoms, are presented and discussed in a comparative way. First of all, following the observations made on the importance of Penning ionization of water by $\operatorname{He}^{*}\left(2^{3} \mathrm{~S}_{1}, 2^{1} \mathrm{~S}_{0}\right)$ and $\mathrm{Ne}^{*}\left({ }^{3} \mathrm{P}_{2,0}\right)$ in the understanding of the chemical composition of Mercury's atmosphere, we report here the mass spectrometric determination of the channel branching ratios for both systems as obtained at an averaged collision energy of $70 \mathrm{meV}$ in the case of $\mathrm{He}^{*}$ and of $55 \mathrm{meV}$ for $\mathrm{Ne}^{*}$ experiments:

$$
\begin{aligned}
\mathrm{He}^{*}+\mathrm{H}_{2} \mathrm{O} & \rightarrow \mathrm{He}+\mathrm{H}_{2} \mathrm{O}^{+}+\mathrm{e}^{-} \\
\rightarrow \mathrm{He}+\mathrm{H}+\mathrm{OH}^{+}+\mathrm{e}^{-} & (18.9 \%) \\
& \rightarrow \mathrm{He}+\mathrm{H}_{2}+\mathrm{O}^{+}+\mathrm{e}^{-}
\end{aligned}
$$

No evidence has been recorded for the $\mathrm{HeH}^{+}, \mathrm{NeH}^{+}$, and $\mathrm{HeH}_{2} \mathrm{O}^{+}, \mathrm{NeH}_{2} \mathrm{O}^{+}$ion production, at least under our experimental conditions. In the case of Penning ionization of ammonia by collisions with neon metastable atoms, the measured yield of possible product ions at an averaged collision energy of $55 \mathrm{meV}$ is:

$$
\begin{aligned}
\mathrm{Ne}^{*}+\mathrm{NH}_{3} & \rightarrow \mathrm{Ne}+\mathrm{NH}_{3}^{+}+\mathrm{e}^{-} \quad(58.8 \%) \\
& \rightarrow \mathrm{Ne}+\mathrm{NH}_{2}^{+}+\mathrm{e}^{-}
\end{aligned}
$$

while, for $\mathrm{Ne}^{*}-\mathrm{H}_{2} \mathrm{~S}$ autoionizing collision in a thermal energy range $(0.02-0.25 \mathrm{eV})$, our spectrometric measurements showed the formation of only the parent $\mathrm{H}_{2} \mathrm{~S}^{+}$product ion.

The ionization of hydrogenated molecules by metastable helium and neon atoms strongly depends on how the molecule is oriented with respect to the approaching excited rare gas atom, determining the 
electronic state of the intermediate ionic complex $[\mathrm{Rg} . . \mathrm{M}]^{+}$and therefore its following reactivity. In fact, for example, a direct probe of the anisotropy of the potential energy surface for $\mathrm{Ne}^{*}-\mathrm{H}_{2} \mathrm{O}$ system can be provided by a comparative analysis of the features of electron energy spectra measured under the same conditions both in photoionization (see Figure 2-upper panel) and in Penning ionization (see Figure 2-lower panel) experiments. All the electron spectra reported in Figure 2 appeared to be composed by two bands: one (at higher electron kinetic energies) for the formation of $\mathrm{H}_{2} \mathrm{O}^{+}$ions (in case of photoionization measurements) and of the $\left[\mathrm{Ne} . \mathrm{H}_{2} \mathrm{O}\right]^{+}$intermediate ionic complex (in Penning ionization determinations) in its ground $\mathrm{X}\left({ }^{2} B_{1}\right)$ electronic state, and another one (at lower electron energy) for the formation of $\mathrm{H}_{2} \mathrm{O}^{+}$and $\left[\mathrm{Ne} \ldots \mathrm{H}_{2} \mathrm{O}\right]^{+}$in their first excited $\mathrm{A}\left({ }^{2} A_{1}\right)$ electronic state. The formation of these two electronic states corresponds to the removal of one electron from one of the two non-bonding orbitals of the neutral molecule. The ground state $\mathrm{X}\left({ }^{2} \mathrm{~B}_{1}\right) \mathrm{H}_{2} \mathrm{O}^{+}$ion is formed by the removal of one electron from the $2 \mathrm{p} \pi$ lone pair orbital, while for the formation of the excited $\mathrm{A}\left({ }^{2} A_{1}\right) \mathrm{H}_{2} \mathrm{O}^{+}$ion, the electron must be removed from the $3 \mathrm{a}_{1} \mathrm{sp}^{2}$ lone pair orbital, as can be seen in Figure 3. Moreover, the "exchange mechanism" for Penning ionization suggests that one outer shell electron of the molecule to be ionized is transferred into the inner shell hole of the excited atom, and then the excess of energy produces the ejection of one electron from the collision complex [14,15].

(a)
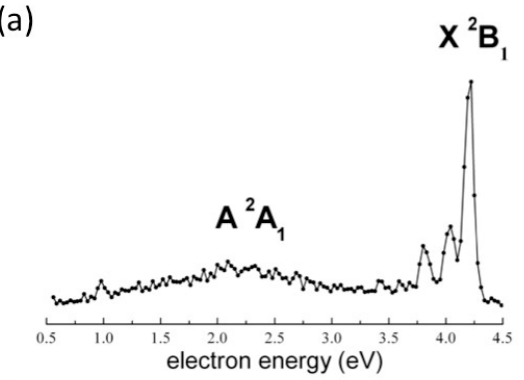

(b)

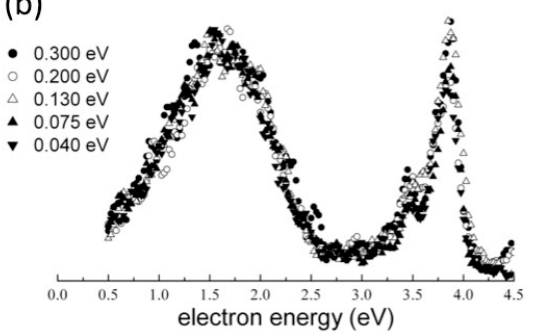

Figure 2. The obtained (a) PES (upper panel) and (b) PIES (lower panel) spectra in photoionization and Penning ionization studies of water molecules using $\mathrm{Ne}(\mathrm{I})$ photons and $\mathrm{Ne}^{*}\left({ }^{3} \mathrm{P}_{2,0}\right)$ metastable atoms, respectively. The PIES spectra reported in the lower panel are recorded at five different collision energies $(0.300,0.200,0.130,0.075$, and $0.040 \mathrm{eV})$, by varying the nozzle temperature (between 300 and $700 \mathrm{~K}$ ) of the supersonic source and by using, besides pure neon, two different $\mathrm{Ne}: \mathrm{H}_{2}$ mixtures (50:50 and 20:80 ratios). By looking at the relative position of the corresponding peak maxima in the PES and PIES spectra, it is possible to evaluate the evident negative energy shifts $\left(-140 \mathrm{meV}\right.$ and $-300 \mathrm{meV}$ for $\mathrm{X}^{2} \mathrm{~B}_{1}$ and $\mathrm{A}^{2} \mathrm{~A}_{1}$ electronic states of $\mathrm{H}_{2} \mathrm{O}^{+}$, respectively) that depend on the binding energy of the autoionizing collision complex (see the text). 
Therefore, we can assert that the two bands in the spectra of Figures 2 and 3 must be related to ionization events occurring with two different geometries of the system: the $\mathrm{X}\left({ }^{2} B_{1}\right)$ band originates from a collision complex with the metastable neon atom perpendicular to the plane of the molecule, while for the $\mathrm{A}\left({ }^{2} A_{1}\right)$ band, at the instant of the ionization, the metastable atom approaches water in the direction of the $\mathrm{C}_{2 \mathrm{v}}$ symmetry axis. In a recent paper [24], by analyzing the energy spectra of the emitted electrons reported in Figure 2 using a novel semiclassical method based on: (i) the assumption that the ionization events are mostly occurring in the vicinities of the collision turning points, and (ii) the formulation of the potential energy driving the system in the relevant configurations of the entrance and exit channels by the use of a semiempirical method developed in our laboratory, we were able to show clearly how different collisional approaches of the metastable atom to the water molecule lead to ions in different electronic states. In particular, we provided the angular acceptance cones where the selectivity of the process leading to the specific formation of each of the two energetically possible ionic product states of $\mathrm{H}_{2} \mathrm{O}^{+}$emerges, showing how the ground state ion is formed when neon metastable atoms approach water mainly perpendicularly to the molecular plane, while the first excited electronic state is formed when the approach occurs preferentially along the $C_{2 v}$ axis, on the oxygen side [24].
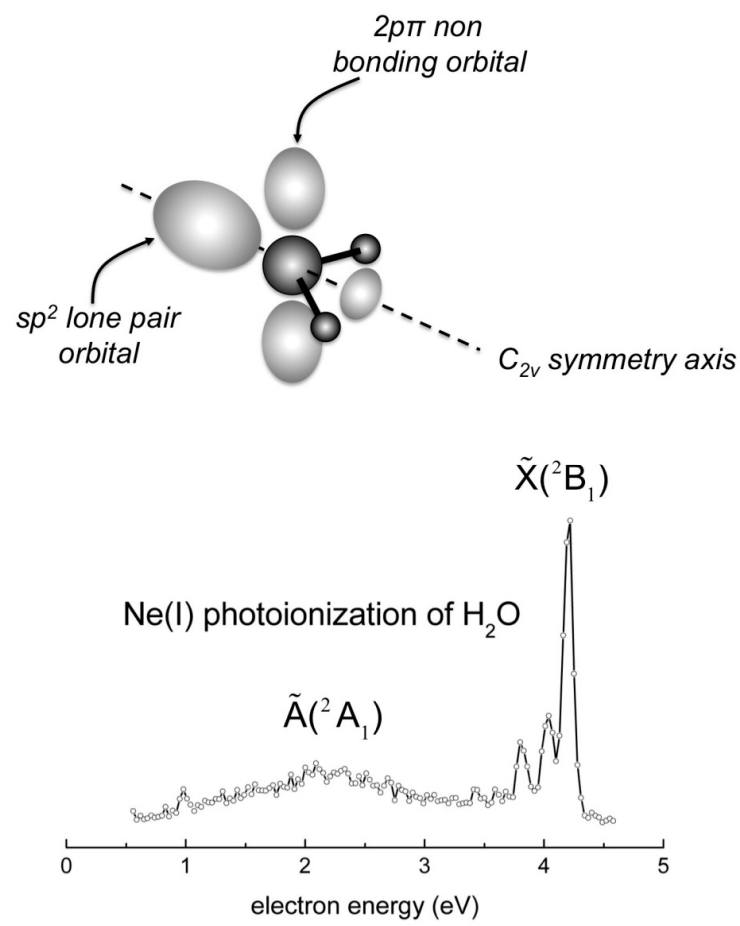

Figure 3. The structure of water molecules in the gas phase, with a $\mathrm{C}_{2 v}$ molecular axis and a sp ${ }^{2}$ hybridization, is depicted. The ground state $\mathrm{X}\left({ }^{2} B_{1}\right) \mathrm{H}_{2} \mathrm{O}^{+}$ion is formed by the removal of one electron from the $2 \mathrm{p} \pi$ lone pair orbital, while for the formation of the excited $\mathrm{A}\left({ }^{2} A_{1}\right)$ $\mathrm{H}_{2} \mathrm{O}^{+}$ion, the electron must be removed from the $3 \mathrm{a}_{1} \mathrm{sp}^{2}$ lone pair orbital. The electron energy spectrum obtained in photoionization of water molecules by using $\mathrm{Ne}(\mathrm{I})$ photons is also shown. The two bands in the spectrum are related to the formation of $\mathrm{H}_{2} \mathrm{O}^{+}$in its ground $\mathrm{X}\left({ }^{2} B_{1}\right)$ electronic state (at higher electron energy), and in the first excited $\mathrm{A}\left({ }^{2} A_{1}\right)$ electronic state (at lower electron energy). 
By analyzing the PES and PIES spectra of Figure 2, recorded in $\mathrm{Ne}(\mathrm{I})$ and $\mathrm{Ne}^{*}-\mathrm{H}_{2} \mathrm{O}$ autoionizing collisions, respectively, we are able to obtain important findings such as the so-called "energy shifts" for the analyzed systems (see Table 2). It is well known that these observables depend on the strength, range, and anisotropy of the effective intermolecular interaction controlling the stereodynamics in the entrance $\mathrm{Rg}^{*}-\mathrm{M}$ (neutral) and the exit $\mathrm{Rg}-\mathrm{M}^{+}$(ionic) channels of ionizing collisional events. In particular, when the position of the maximum of a certain peak in the PIES spectrum exhibits a sizeable negative shift, here referred to as $\varepsilon_{\max }$, with respect to the nominal energy, $\varepsilon_{0}$ (defined as the difference between the excitation energy of the metastable $\mathrm{He}^{*}$ or $\mathrm{Ne}^{*}$ atoms and the ionization potential of the relevant molecular state), this is an indication that a phenomenological global attractive interaction drives the collision dynamics of the partners on a multidimensional potential energy surface, including entrance and exit channels [23,36]. These energy shifts are also determined by looking at the relative position of the corresponding peak maxima in the PES and PIES spectra. For example, analyzing in a comparative way the electron spectra of Figure 2, it is possible to clearly note that both peak maxima for $\mathrm{X}$ and $\mathrm{A}$ states of produced $\mathrm{H}_{2} \mathrm{O}^{+}$ions are shifted at lower electron kinetic energy values in the case of Penning ionization spectra with respect to the photoionization ones. The absolute values of these shifts are much higher than the difference between the energy content of the $\mathrm{Ne}^{*}$ metastable atoms and the energy of the $\mathrm{Ne}(\mathrm{I})$ photons, because of the strong attractive interaction potential between the incoming collisional partners $\mathrm{Ne}^{*}-\mathrm{H}_{2} \mathrm{O}$ (for a detailed description, see for instance [22]). In general, as the $\mathrm{Rg}^{*}-\mathrm{M}$ attractive interaction is stronger, a more negative energy shift is expected between PES- and PIES-recorded spectra. These considerations are confirmed by our mass spectrometric determinations, and, in particular, by the total ionization cross-section measurement as a function of the collision energy reported in Figure 4. It is interesting to note that the cross-section shows a decreasing trend as the collision energy increases and, further, its absolute value is quite big (of about $50 \AA^{2}$ at $70 \mathrm{meV}$ ). Accordingly to the well-known peculiarity of Penning ionization processes [14,15], both these characteristics are a clear confirmation of the strong binding behavior of the $\mathrm{Ne}^{*}-\mathrm{H}_{2} \mathrm{O}$ autoionizing collision complex, due to the strong attractive nature of the system because of the intense molecular dipole of the water molecule $(\mu=1.85 \mathrm{D})$.

Analyzing the PES and PIES spectra for $\mathrm{Ne}(\mathrm{I})$ and $\mathrm{Ne}^{*}-\mathrm{H}_{2} \mathrm{~S}, \mathrm{NH}_{3}$ systems, respectively, by using the same procedure already described for water molecules, we have been able to determine the related energy shifts, as shown in Figure 5 (see also Table 2). All the measured shifts have a negative value, indicating again an attractive behavior for the potential energy surface in the entrance $\mathrm{Ne}^{*}-\mathrm{M}$ channel (where $\mathrm{M}=\mathrm{H}_{2} \mathrm{~S}, \mathrm{NH}_{3}$ ) as in the case of $\mathrm{Ne}^{*}-\mathrm{H}_{2} \mathrm{O}$ autoionizing collisions. This attractive behavior is stronger in the formation of $\mathrm{Ne}^{*}-\mathrm{H}_{2} \mathrm{O}$, whose energy shifts are $-140 \pm 20$ and $-300 \pm 20 \mathrm{meV}$ for the $\mathrm{X}\left({ }^{2} B_{1}\right)$ and $\mathrm{A}\left({ }^{2} A_{1}\right)$ bands, respectively; it is less intense in the case of $\mathrm{Ne}^{*}-\mathrm{H}_{2} \mathrm{~S}$ collisions (energy shifts of $-80 \pm 20$ and $-120 \pm 20$ for the same two $\mathrm{X}\left({ }^{2} B_{1}\right)$ and $\mathrm{A}\left({ }^{2} A_{1}\right)$ bands, respectively); while in the case of $\mathrm{Ne}^{*}-\mathrm{NH}_{3}$ (energy shifts of $-290 \pm 20$ and $-140 \pm 20$ for the two $\mathrm{X}\left({ }^{2} A 2^{\prime \prime}\right)$ and $\mathrm{A}\left({ }^{2} E\right)$ bands, respectively) the attractive interaction component, affecting the entrance channel of the potential energy surface, favors those collisions producing the $\left[\mathrm{Ne} . . . \mathrm{NH}_{3}\right]^{+}$intermediate ionic complex in its $\mathrm{X}\left({ }^{2} A 2^{\prime}\right)-3 \mathrm{a}_{1}$ ground electronic state. The formation of $\left[\mathrm{Ne} . . \mathrm{NH}_{3}\left(\mathrm{X}^{2} A_{2}{ }^{\prime \prime}\right)\right]^{+}$occurs preferentially when the neon metastable atom is approaching ammonia molecules towards the direction of the 3a1 non-bonding lone pair located on the nitrogen atom and removes one electron from this orbital, producing Penning ionization. 

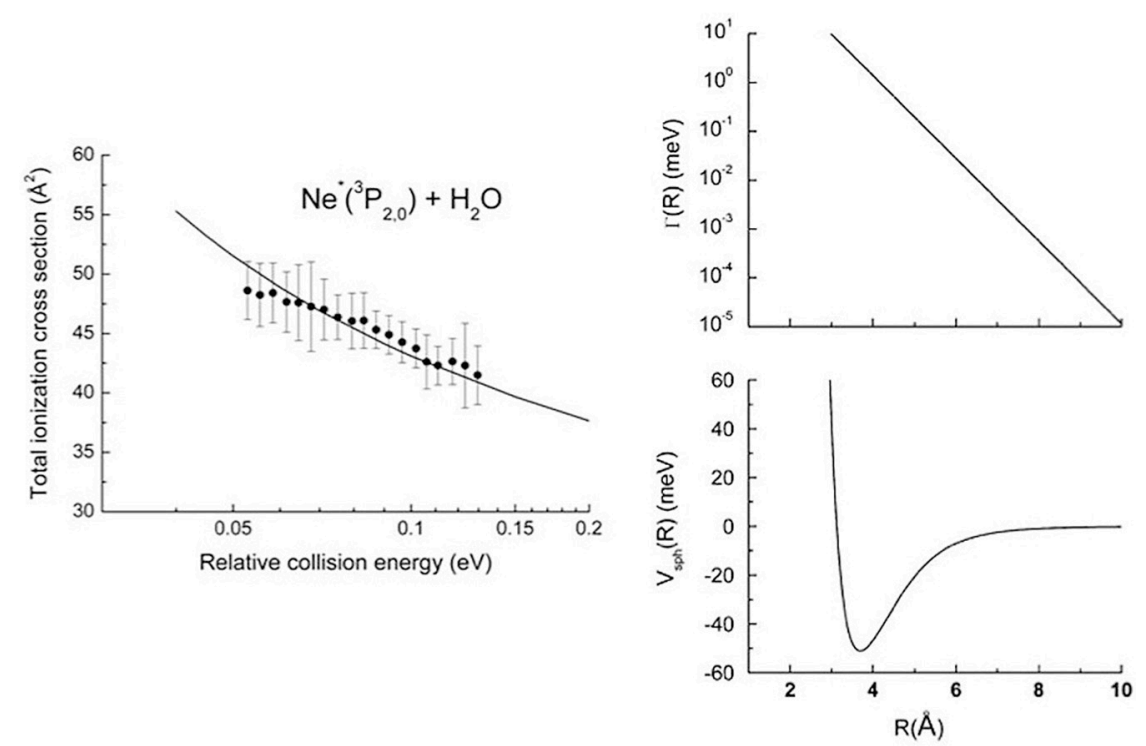

Figure 4. Left side: The total ionization cross-sections of the $\mathrm{Ne}^{*}-\mathrm{H}_{2} \mathrm{O}$ autoionizing collisions as a function of the relative collision energy. The curve represents the calculation of the cross-section by applying the theory defined in terms of the so-called optical potential model, which exploits the recorded energy shifts from the electron kinetic energy spectra to probe the main characteristics of the potential energy surface for the $\mathrm{Ne}^{*}-\mathrm{H}_{2} \mathrm{O}$ entrance channel (see the text and Figure 2) [14,15,22]. Right side: The spherical optical potential used for the cross-section calculation (see left side of this figure). Lower panel represents the real part of the optical potential, while the upper panel is the imaginary part (see the text and [23]).

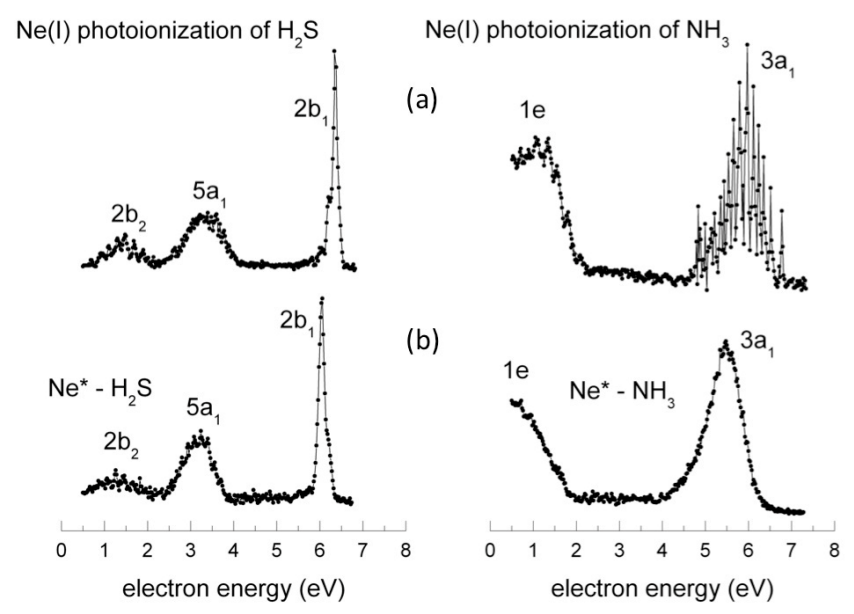

Figure 5. The obtained (a) PES (upper panel) and (b) PIES (lower panel) spectra in photoionization and Penning ionization studies of hydrogen sulfide (left side) and ammonia (right side) molecules by using $\mathrm{Ne}(\mathrm{I})$ photons and $\mathrm{Ne}^{*}\left({ }^{3} \mathrm{P}_{2,0}\right)$ metastable atoms, respectively. By looking at the relative position of the corresponding peak maxima in the PES and PIES spectra for both investigated systems, it is possible to measure the negative energy shifts ( $-80 \mathrm{meV}$ and $-120 \mathrm{meV}$ for $2 \mathrm{~b}_{1}$ and $5 \mathrm{a}_{1}$ electronic states of $\mathrm{H}_{2} \mathrm{~S}^{+}$, respectively; and $-290 \mathrm{meV}$ and $-140 \mathrm{meV}$ for $3 \mathrm{a}_{1}$ and 1 e electronic states of $\mathrm{NH}_{3}{ }^{+}$), with the same procedure used in the $\mathrm{Ne}^{*}-\mathrm{H}_{2} \mathrm{O}$ case (see Figure 2 and the text). 
The measured energy shifts for the three investigated systems are compared in Table 2, where are also reported those extracted from the measured PIES spectra for $\mathrm{He}^{*}-\mathrm{H}_{2} \mathrm{~S}$ and $\mathrm{NH}_{3}$ autoionizing collisions (see Figure 6). Also in these cases we recorded negative energy shifts having a bigger value, indicating a more attractive behavior in the case of $\mathrm{He}^{*}-\mathrm{M}$ collisions respect to $\mathrm{Ne}^{*}-\mathrm{M}$ collisions (with $\mathrm{M}=\mathrm{H}_{2} \mathrm{~S}, \mathrm{NH}_{3}$ ). This observation is in fairly good agreement with previous results obtained by Ohno et al. [27] and Ben Arfa et al. [39] for $\mathrm{He}^{*}-\mathrm{H}_{2} \mathrm{O}$ collisions, and can be justified in terms of the higher electronic polarizability of $\mathrm{He}^{*}$ atoms (118.9 and $46.9 \AA^{3}$ for $2^{1} \mathrm{~S}_{0}$ and $2^{3} \mathrm{~S}_{1}$ spin-orbit states, respectively) with respect to that of $\mathrm{Ne}^{*}\left(27.8 \AA^{3}\right.$ for the ${ }^{3} \mathrm{P}_{2}$ state), which is the fundamental physical property of the partners, enhancing the attractive interaction behavior of the potential energy surfaces [22].

Table 2. Negative energy shifts from the PIES $\mathrm{He}^{*}$ and $\mathrm{Ne}^{*}-\mathrm{H}_{2} \mathrm{O}, \mathrm{H}_{2} \mathrm{~S}$ and $\mathrm{NH}_{3}$ spectra measured at an average collision energy of 70 and $55 \mathrm{meV}$, respectively.

\begin{tabular}{|c|c|c|}
\hline & \multicolumn{2}{|c|}{ Shifts with Respect to Nominal Energy $\varepsilon_{0}(\mathrm{meV})$} \\
\hline Band in PIES & $\mathrm{H}_{2} \mathrm{O}^{+}\left(\mathrm{X}^{2} B_{1}\right)-1 \mathrm{~b}_{1}$ & $\mathrm{H}_{2} \mathrm{O}^{+}\left(\mathrm{A}^{2} A_{1}\right)-3 \mathrm{a}_{1}$ \\
\hline $\begin{array}{l}\text { maximum of peak }(\mathrm{v}=0) \varepsilon_{\max } \\
\text { for } \mathrm{He}^{*}\left({ }^{3} \mathrm{~S}_{1}\right) \text { collisions }\end{array}$ & $-440^{1}$ & $-485^{1, *}$ \\
\hline $\begin{array}{l}\text { maximum of peak }(\mathrm{v}=0) \varepsilon_{\max } \\
\text { for } \mathrm{He}^{*}\left({ }^{1} \mathrm{~S}_{0}\right) \text { collisions }\end{array}$ & $-720^{2}$ & $-700^{2, *}$ \\
\hline $\begin{array}{l}\text { maximum of peak }(\mathrm{v}=0) \varepsilon_{\max } \\
\text { for } \mathrm{Ne}^{*} \text { collisions }\end{array}$ & $-140 \pm 20$ & $-300 \pm 20 *$ \\
\hline $\begin{array}{l}44 \% \text { of maximum }(\mathrm{v}=0) \varepsilon_{\mathrm{A}} \\
\text { for } \mathrm{Ne}^{*} \text { collisions }\end{array}$ & $-320 \pm 20$ & Not evaluable \\
\hline Band in PIES & $\mathrm{H}_{2} \mathrm{~S}^{+}\left(\mathrm{X}^{2} B_{1}\right)-2 \mathrm{~b}_{1}$ & $\mathrm{H}_{2} \mathrm{~S}^{+}\left(\mathrm{A}^{2} A_{1}\right)-5 \mathrm{a}_{1}$ \\
\hline $\begin{array}{l}\text { maximum of peak }(\mathrm{v}=0) \varepsilon_{\max } \\
\text { for } \mathrm{He}^{*}\left({ }^{3} \mathrm{~S}_{1}\right) \text { collisions }\end{array}$ & $-150 \pm 20$ & $-190 \pm 20 *$ \\
\hline $\begin{array}{l}\text { maximum of peak }(\mathrm{v}=0) \varepsilon_{\max } \\
\text { for } \mathrm{He}^{*}\left({ }^{1} \mathrm{~S}_{0}\right) \text { collisions }\end{array}$ & $-220 \pm 20$ & $-230 \pm 20 *$ \\
\hline $\begin{array}{l}\text { maximum of peak }(\mathrm{v}=0) \varepsilon_{\max } \\
\text { for } \mathrm{Ne}^{*} \text { collisions }\end{array}$ & $-80 \pm 20$ & $-120 \pm 20 *$ \\
\hline $\begin{array}{l}44 \% \text { of maximum }(\mathrm{v}=0) \varepsilon_{\mathrm{A}} \\
\text { for } \mathrm{Ne}^{*} \text { collisions }\end{array}$ & $-195 \pm 20$ & Not evaluable \\
\hline Band in PIES & $\mathrm{NH}_{3}^{+}\left(\mathrm{X}^{2} \mathrm{~A}_{2}{ }^{\prime \prime}\right)-3 \mathrm{a}_{1}$ & $\mathrm{NH}_{3}^{+}\left(\mathrm{A}^{2} \mathrm{E}\right)-1 \mathrm{e}$ \\
\hline $\begin{array}{l}\text { maximum of peak }(\mathrm{v}=0) \varepsilon_{\max } \\
\text { for } \mathrm{He}^{*}\left({ }^{3} \mathrm{~S}_{1}\right) \text { collisions }\end{array}$ & $-450 \pm 20$ & $-350 \pm 20 *$ \\
\hline $\begin{array}{l}\text { maximum of peak }(\mathrm{v}=0) \varepsilon_{\max } \\
\text { for } \mathrm{He}^{*}\left({ }^{1} \mathrm{~S}_{0}\right) \text { collisions }\end{array}$ & $-585 \pm 20$ & Not evaluable \\
\hline $\begin{array}{l}\text { maximum of peak }(\mathrm{v}=0) \varepsilon_{\max } \\
\text { for } \mathrm{Ne}^{*} \text { collisions }\end{array}$ & $-290 \pm 20$ & $-140 \pm 20 *$ \\
\hline $\begin{array}{l}44 \% \text { of maximum }(\mathrm{v}=0) \varepsilon_{\mathrm{A}} \\
\text { for } \mathrm{Ne}^{*} \text { collisions }\end{array}$ & $-840 \pm 20$ & Not evaluable \\
\hline
\end{tabular}

*: evaluated from the maximum of band; ${ }^{1}$ : from [19]; ${ }^{2}$ : from [32].

As already discussed in previous papers [22,23], by a simple analysis of obtained PIES spectra, in the case of $\mathrm{H}_{2} \mathrm{O}^{+}-1 b_{1}, \mathrm{H}_{2} \mathrm{~S}^{+}-2 b_{1}$, and $\mathrm{NH}_{3}{ }^{+}-3 \mathrm{a}_{1}$ ground states it is possible to extract not only the negative 
shift, \&max, from the change in position of the maximum of peak but also the shift between the electron energy value where the peak intensity drops down to $44 \%$ of its maximum at the lower energy side, $\varepsilon_{\mathrm{A}}$, with respect to the nominal energy, $\varepsilon_{0}$ [40]. For a detailed description of the theory of Penning ionization with a full discussion of the relation between the measured energy shifts from recorded PIES spectra and the main characteristics of the related potential energy surfaces, we refer to the important and basic paper of H.W. Miller published in 1970 [40]. The obtained values amount to $-320 \pm 20 \mathrm{meV}$ for $\mathrm{Ne}^{*}-\mathrm{H}_{2} \mathrm{O}$ collisions, $-195 \pm 20 \mathrm{meV}$ for $\mathrm{Ne}^{*}-\mathrm{H}_{2} \mathrm{~S}$ collisions, and $-840 \pm 20 \mathrm{meV}$ for $\mathrm{Ne}^{*}-\mathrm{NH}_{3}$ collisions, and they are also reported in Table 2. These findings confirm the occurrence of a very strong attractive behavior of $\mathrm{Ne}^{*}-\mathrm{NH}_{3}$ interaction promoting the Penning process, which leads to the formation of the molecular ion in the ground electronic state. A still quite strong attractive behavior drives the $\mathrm{Ne}^{*}-\mathrm{H}_{2} \mathrm{O}$ collisions, while the corresponding attraction in the $\mathrm{Ne}^{*}-\mathrm{H}_{2} \mathrm{~S}$ collisions appears to be about $40 \%$ smaller than in the case of water. This consideration comes from the suggestion by Haug et al. [28], who noted that the energy shift $\varepsilon_{\mathrm{A}}$ can be used as a proper indication of the depth of the attractive potential well of the interaction between the colliding particles in the entrance channel. This suggestion is reasonable considering the weaker attraction in the exit channel due to the very low polarizability of neon atoms $\left(0.40 \AA^{3}\right)$ in the ground electronic state with respect to that in the excited ones $\left(27.8 \AA^{3}\right)$. In our case, the estimate of $\varepsilon_{A}$ can be done only for the interaction of $\mathrm{Ne}^{*}$ approaching the $\mathrm{H}_{2} \mathrm{O}, \mathrm{H}_{2} \mathrm{~S}$, and $\mathrm{NH}_{3}$ molecules and producing $\left[\mathrm{Ne} \ldots \mathrm{H}_{2} \mathrm{O}\right]^{+},\left[\mathrm{Ne} \ldots \mathrm{H}_{2} \mathrm{~S}\right]^{+}$and $\left[\mathrm{Ne} . . \mathrm{NH}_{3}\right]^{+}$intermediate ionic complexes in the $\left(\mathrm{X}^{2} B_{1}\right)-1 b_{1}$, $\left(\mathrm{X}^{2} B_{1}\right)-2 \mathrm{~b}_{1}$, and $\left(\mathrm{X}^{2} A_{2}{ }^{\prime \prime}\right)-2 \mathrm{~b}_{1}$ ground electronic states, respectively. An analogous evaluation of $\varepsilon_{\mathrm{A}}$ for the $\left(\mathrm{A}^{2} A_{1}\right)$ and $\left(\mathrm{A}^{2} E\right)$ excited states of $\left[\mathrm{Ne} \ldots \mathrm{H}_{2} \mathrm{O}\right]^{+},\left[\mathrm{Ne} \ldots \mathrm{H}_{2} \mathrm{~S}\right]^{+}$and $\left[\mathrm{Ne} . . . \mathrm{NH}_{3}\right]^{+}$intermediate ionic complexes is not possible because in these cases the recorded broad bands in the PIES spectra do not satisfy the features required by the theory [28,40-42].

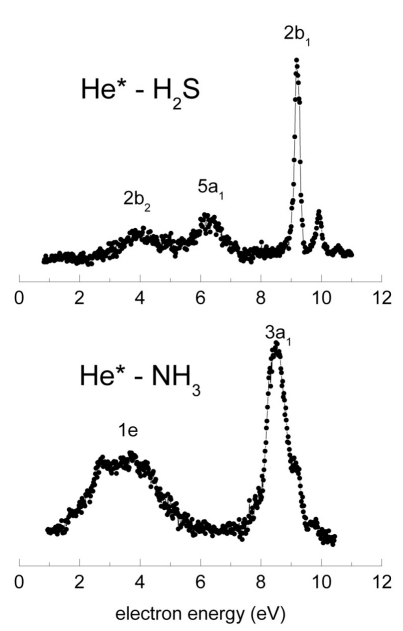

Figure 6. The obtained PIES spectra in Penning ionization studies of hydrogen sulfide (upper panel) and ammonia (lower panel) molecules by using $\mathrm{He}^{*}\left({ }^{3} \mathrm{~S}_{1},{ }^{1} \mathrm{~S}_{0},\right)$ metastable atoms. In the $2 b_{1}$ band of the $\mathrm{He}^{*}-\mathrm{H}_{2} \mathrm{~S}$ spectrum, the two peaks recorded at an electron energy value of 9.18 and $9.94 \mathrm{eV}$, and related to $\mathrm{He}^{*}\left({ }^{3} \mathrm{~S}_{1}\right)$ and $\mathrm{He}^{*}\left({ }^{1} \mathrm{~S}_{0}\right)$ collisional ionization events, respectively, appear well separated (see upper panel). The two $\mathrm{He}^{*}\left({ }^{3} \mathrm{~S}_{1},{ }^{1} \mathrm{~S}_{0}\right.$, ) metastable components are still present, even if less separated, in the wide $3 \mathrm{a}_{1}$ band of the $\mathrm{He}^{*}-\mathrm{NH}_{3}$ spectrum (see lower panel). 


\section{Conclusions}

Considering that a basic step in the chemical evolution of planetary atmospheres and interstellar clouds (where $89 \%$ of atoms are hydrogen and $9 \%$ are helium) is the interaction of atoms and molecules with electromagnetic waves ( $\gamma$ and $X$ rays, UV light) and cosmic rays [43], the formation of excited metastable species like $\mathrm{He}^{*}$ and $\mathrm{Ar}^{*}$ (argon is the third component of Earth and Mars' atmosphere) by collisional excitation with energetic target particles (electrons, protons, or alpha particles, coming from the solar wind) and the possible subsequent Penning ionization reactions, could be of importance in these environments. It has to be stressed that the effect of Penning ionization has not yet been fully considered in the modeling of terrestrial and extraterrestrial objects, even though metastable excited species can be formed in such environments. In this paper recent experimental results concerning production and characterization of simple ionic species of atmospheric interest are presented and discussed. Such results concern the formation of free ions in collisional ionization of $\mathrm{H}_{2} \mathrm{O}, \mathrm{H}_{2} \mathrm{~S}$, and $\mathrm{NH}_{3}$ induced by highly excited species, like $\mathrm{He}^{*}$ and $\mathrm{Ne}^{*}$ metastable atoms.

The analysis of the recorded electron spectra for the three presented systems clearly shows: (i) a very strong and anisotropic attractive behavior of $\mathrm{Ne}^{*}-\mathrm{NH}_{3}$ interaction promoting the Penning process; (ii) a still quite strong attractive behavior for $\mathrm{Ne}^{*}-\mathrm{H}_{2} \mathrm{O}$ collisions; and (iii) a corresponding attractive interaction in the $\mathrm{Ne}^{*}-\mathrm{H}_{2} \mathrm{~S}$ collisions, which appear to be about $40 \%$ that of water. The analyzed experimental observables, in term of energy shifts, clearly indicate that $\mathrm{H}_{2} \mathrm{O}$ and $\mathrm{H}_{2} \mathrm{~S}$ show similar behavior when these hydrogenated molecules are involved in Penning ionization induced by $\mathrm{He}^{*}$ and $\mathrm{Ne}^{*}$ metastable atoms, and in particular: (i) the interaction potential driving the formation of $\mathrm{A}^{2} \mathrm{~A}_{1}$ excited state of $\mathrm{H}_{2} \mathrm{O}^{+}$and $\mathrm{H}_{2} \mathrm{~S}^{+}$product ions exhibits an effective interaction potential well depth in the entrance channel of the ionization reaction, quite deeper (about 50\% more in the case of water and about $25 \%$ more in the case of hydrogen sulfide) than that involved in the production of the same final ions in their $\mathrm{X}^{2} \mathrm{~B}_{1}$ ground state (see the relative $\varepsilon_{\max }$ values reported in the Table 2); (ii) a quite pronounced anisotropic attraction controls the stereodynamics in the entrance channels of both $\left(\mathrm{Ne}^{*}-\mathrm{H}_{2} \mathrm{O}, \mathrm{H}_{2} \mathrm{~S}\right)$ analyzed systems: in the case of $\mathrm{Ne}^{*}-\mathrm{H}_{2} \mathrm{O}$ autoionizing collisions a strong anisotropic interaction is operative, while in the $\mathrm{Ne}^{*}-\mathrm{H}_{2} \mathrm{~S}$ system the attractive interaction appears to be weaker than the system involving water; and (iii) the entity of this smaller attraction, characterizing $\mathrm{Ne}^{*}-\mathrm{H}_{2} \mathrm{~S}$ collisions, is dependent on the approach orientation between $\mathrm{Ne}^{*}$ atoms and the hydrogenated target molecules: it is about $43 \%$ with respect to the $\mathrm{Ne}^{*}-\mathrm{H}_{2} \mathrm{O}$ case for those collisions producing $\mathrm{H}_{2} \mathrm{X}^{+}$parent ions (where $\mathrm{X}$ stands for $\mathrm{O}$ or $\mathrm{S}$ atom) in their $\mathrm{X}^{2} \mathrm{~B}_{1}$ ground electronic state (this is the case for the $\mathrm{Ne}^{*}-\mathrm{H}_{2} \mathrm{X}$ collisions towards the orthogonal direction respect to the molecular plane), while it reaches about $60 \%$ of the $\mathrm{Ne}^{*}-\mathrm{H}_{2} \mathrm{O}$ interaction when the exchange mechanism of Penning ionization can exploit $\mathrm{Ne}^{*}$ collisions along the $\mathrm{C}_{2 \mathrm{v}}$ molecular axis in the opposite side with respect to hydrogen atoms, with the formation of $\mathrm{H}_{2} \mathrm{X}^{+}$final ions in their first $\mathrm{A}^{2} \mathrm{~A}_{1}$ excited electronic state. In the case of $\mathrm{Ne}^{*}-\mathrm{NH}_{3}$ collisions, a very strong and anisotropic attractive interaction is observed, characterizing the potential energy surface of the entrance channel with a much deeper well depth in the case of those collisions producing the $\left[\mathrm{Ne} . . \mathrm{NH}_{3}\right]^{+}$intermediate ionic complex, leading product ion in its $\mathrm{X}\left({ }^{2} A_{2}{ }^{\prime \prime}\right)-3 \mathrm{a}_{1}$ ground electronic state (which is an opposite situation to that observed in $\mathrm{H}_{2} \mathrm{O}$ and $\mathrm{H}_{2} \mathrm{~S}$ systems). In this case the formation of $\left[\mathrm{Ne} . . . \mathrm{NH}_{3}\left(\mathrm{X}^{2} A_{2}{ }^{\prime \prime}\right)\right]^{+}$occurs preferentially when the neon metastable atom approaches ammonia molecules towards the direction of the $3 \mathrm{a}_{1}$ non-bonding lone pair located on the nitrogen atom, removes 
one electron from this orbital, and gives rise to Penning ionization. Finally, the analysis of PIES spectra recorded for $\mathrm{He}^{*}-\mathrm{H}_{2} \mathrm{~S}$ and $-\mathrm{NH}_{3}$ collisions, confirms the attractive and anisotropic behavior of the potential energy surfaces already discussed for $\mathrm{Ne}^{*}-\mathrm{M}$ interactions (with $\mathrm{M}=\mathrm{H}_{2} \mathrm{O}, \mathrm{H}_{2} \mathrm{~S}$, and $\mathrm{NH}_{3}$ ) governing the entrance channel for Penning ionization of such hydrogenated molecules. A similar situation for metastable helium and metastable neon atoms interacting with $\mathrm{N}_{2} \mathrm{O}$ molecules [19] has been explained by the use of a semiempirical method that accounts for the metastable atom orbital deformation because of the permanent dipole of the molecule. We have plans to extend such a model also to the systems presented here, and to test the potential energy surfaces so obtained in a comparative way. This work, is in progress in our laboratory, will allow us to achieve a deeper understanding of the stereodynamics of the collisional autoionization processes involving $\mathrm{He}^{*}$ and $\mathrm{Ne}^{*}$ with the hydrogenated molecules here discussed, and of the propensity to form ions.

\section{Acknowledgments}

Stefano Falcinelli is very grateful to Richard N. Zare of the Chemistry Department of Stanford University, CA, USA, for his constant encouragement and the useful suggestions during the period between June and September 2014 when Stefano Falcinelli was working in his laboratory as a visiting scholar and was conceiving the paper here presented.

\section{Author Contributions}

Stefano Falcinelli and Franco Vecchiocattivi conceived and designed the experiment; Stefano Falcinelli performed the experiment; Fernando Pirani developed the semiempirical method for potential energy surfaces calculations; all the authors analyzed the data, participated to the discussion on the obtained results, and contributed to write the paper.

\section{Conflicts of Interest}

The authors declare no conflict of interest.

\section{References}

1. Davies, K.; Rush, C.M. Reflection of high-frequency radio waves in inhomogeneous ionospheric layers. Radio Sci. 1985, 20, 303-309.

2. Hruska, F. Electromagnetic Interference and Environment. Int. J. Circuits Syst. Signal Process. 2014, 8, 22-29.

3. Qiu, H.; Chen, L.T.; Qiu, G.P.; Zhou, C. 3D visualization of radar coverage considering electromagnetic interference. WSEAS Trans. Signal Process. 2014, 10, 460-470.

4. Egano, F. Radio Propagation Observatory. Available online: http://www.qsl.net/ik3xtv (accessed on 14 August 2014).

5. Hotop, H. Detection of metastable atoms and molecules. In Atomic, Molecular, and Optical Physics: Atoms and Molecules; Dunning, F.B., Hulet, R.G., Eds.; Academic Press, Inc.: San Diego, CA, USA, 1996; pp. 191-216. 
6. Brunetti, B.G.; Falcinelli, S.; Giaquinto, E.; Sassara, A.; Prieto-Manzanares, M.; Vecchiocattivi, F. Metastable-Idrogen-Atom scattering by crossed beams: Total cross sections for $\mathrm{H}^{*}(2 \mathrm{~s})-\mathrm{Ar}$, Xe, and $\mathrm{CCl}_{4}$ at thermal energies. Phys. Rev. A 1995, 52, 855-858.

7. Falcinelli, S. Penning ionization of simple molecules and their possible role in planetary atmospheres. In Recent Advances in Energy, Environment and Financial Planning-Mathematics and Computers in Science and Engineering Series; Batzias, F., Mastorakis, N.E., Guarnaccia, C., Eds.; WSEAS Press: Athens, Greece, 2014; pp. 84-92.

8. Rodger, C.J.; Nunn, D. VLF scattering from red sprites: Application of numerical modeling. Radio Sci. 1999, 34, 923-932.

9. Larsson, M.; Geppert, W.D.; Nyman, G. Ion chemistry in space. Rep. Prog. Phys. 2012, 75, 066901.

10. Stauber, P.; Doty, S.D.; van Dishoeck, E.F.; Benz, A.O. X-ray chemistry in the envelopes around young stellar objects. Astron. Astrophys. 2005, 440, 949-966.

11. Indriolo, N.; Hobbs, L.M.; Hinkle, K.H.; McCall, B.J. Interstellar metastable helium absorption as a probe of the cosmic-ray ionization rate. Astrophys. J. 2009, 703, 2131-2137.

12. Waldrop, L.S.; Kerr, R.B.; González, S.A.; Sulzer, M.P.; Noto, J.; Kamalabadi, F. Generation of metastable helium and $1083 \mathrm{~nm}$ emission in the upper thermosphere. J. Geophys. Res. 2005, 110, A08304.

13. Bishop, J.; Link, R. He $\left(2^{3} \mathrm{~S}\right)$ densities in the upper thermosphere: Updates in modeling capabilities and comparison with midlatitude observations. J. Geophys. Res. 2005, 104, 17157-17172.

14. Siska, P.E. Molecular-beam studies of Penning ionization. Rev. Mod. Phys. 1993, 65, 337-412.

15. Brunetti, B.G.; Vecchiocattivi, F. Autoionization dynamics of collisional complexes. In Ion Clusters; Ng, C., Baer, T., Powis, I., Eds.; Springer: New York, NY, USA, 1993; pp. 359-445.

16. Penning, F.M. Über Ionisation durch metastabile Atome. Naturwissenschaften. J. 1927, 15, doi:10.1007/BF01505431

17. Legon, A.C. The halogen bond: An interim perspective. Phys. Chem. Chem. Phys. 2010, 12, 7736-7747.

18. Biondini, F.; Brunetti, B.G.; Candori, P.; de Angelis, F.; Falcinelli, S.; Tarantelli, F.; Teixidor, M.M.; Pirani, F.; Vecchiocattivi, F. Penning ionization of $\mathrm{N}_{2} \mathrm{O}$ molecules by $\mathrm{He}^{*}\left(2^{3,1} \mathrm{~S}\right)$ and $\mathrm{Ne}^{*}\left({ }^{3} \mathrm{P}_{2,0}\right)$ metastable atoms: A crossed beam study. J. Chem. Phys. 2005, 122, 164307:1-164307:10.

19. Biondini, F.; Brunetti, B.G.; Candori, P.; de Angelis, F.; Falcinelli, S.; Tarantelli, F.; Pirani, F.; Vecchiocattivi, F. Penning ionization of $\mathrm{N}_{2} \mathrm{O}$ molecules by $\mathrm{He}^{*}\left(2^{3,1} \mathrm{~S}\right)$ and $\mathrm{Ne}^{*}\left({ }^{3} \mathrm{P}_{2,0}\right)$ metastable atoms: Theoretical considerations about the intermolecular interactions. J. Chem. Phys. 2005, 122, 164308:1-164308:11.

20. McClintock, W.E.; Lankton, M.R. The mercury atmospheric and surface composition spectrometer for the MESSENGER mission. J. Phys. Chem. Ref. Data 1989, 21, 1125-1499.

21. Atkinson, R.; Baulch, D.L.; Cox, R.A.; Hampson, R.F.; Kerr, J.A., Jr.; Troe, J. Evaluated kinetic and photochemical data for atmospheric chemistry: Supplement IV. IUPAC Subcommittee on kinetic data evaluation for atmospheric chemistry. Space Sci. Rev. 2007, 131, 481-521.

22. Brunetti, B.G.; Candori, P.; Cappelletti, D.; Falcinelli, S.; Pirani, F.; Stranges, D.; Vecchiocattivi, F. Penning ionization electron spectroscopy of water molecules by metastable neon atoms. Chem. Phys. Lett. 2012, 539-540, 19-23. 
23. Balucani, N.; Bartocci, A.; Brunetti, B.G.; Candori, P.; Falcinelli, S.; Pirani, F.; Palazzetti, F.; Vecchiocattivi, F. Collisional autoionization dynamics of $\mathrm{Ne}^{*}\left({ }^{3} \mathrm{P}_{2,0}\right)-\mathrm{H}_{2} \mathrm{O}$. Chem. Phys. Lett. 2012, 546, 34-39.

24. Brunetti, B.G.; Candori, P.; Falcinelli, S.; Pirani, F.; Vecchiocattivi, F. The stereodynamics of the Penning ionization of water by metastable neon atoms. J. Chem. Phys. 2013, 139, 164305:1-164305:8.

25. Čermák, V.; Yencha, A.J. Penning ionization electron spectroscopy of $\mathrm{H}_{2} \mathrm{O}, \mathrm{D}_{2} \mathrm{O}, \mathrm{H}_{2} \mathrm{~S}$ and $\mathrm{SO}_{2}$. J. Electron Spectr. Rel. Phenom. 1977, 11, 67-73.

26. Brion, C.E.; Yee, D.S.C. Electron spectroscopy using excited atoms and photons IX. Penning ionization of $\mathrm{CO}_{2}, \mathrm{CS}_{2}, \mathrm{COS}, \mathrm{N}_{2} \mathrm{O}, \mathrm{H}_{2} \mathrm{~S}, \mathrm{SO}_{2}$, and $\mathrm{NO}_{2}$. J. Electron Spectr. Rel. Phenom. 1977, 12 , 77-93.

27. Ohno, K.; Mutoh, H.; Harada, Y. Study of electron distributions of molecular orbitals by Penning ionization electron spectroscopy. J. Am. Chem. Soc. 1983, 105, 4555-4561.

28. Haug, B.; Morgner, H.; Staemmler, V. Experimental and theoretical study of Penning ionisation of $\mathrm{H}_{2} \mathrm{O}$ by metastable Helium He $\left(2^{3}\right.$ S). J. Phys. B At. Mol. Phys. 1985, 18, 259-274.

29. Bentley, J. Potential energy surfaces for excited neon atoms interacting with water molecules. J. Chem. Phys. 1980, 73, 1805-1813.

30. Ishida, T. A quasi-classical trajectory calculation for the Penning ionization $\mathrm{H}_{2} \mathrm{O}-\mathrm{He}^{*}\left(2^{3} \mathrm{~S}\right)$. J. Chem. Phys. 1996, 105, 1392-1401.

31. Falcinelli, S.; Candori, P.; Bettoni, M.; Pirani, F.; Vecchiocattivi, F. Penning ionization electron spectroscopy of hydrogen sulfide by metastable Helium and Neon atoms. J. Phys. Chem. A 2014, 118, 6501-6506.

32. Arfa, M.B.; Lescop, B.; Cherid, M.; Brunetti, B.; Candori, P.; Malfatti, D.; Falcinelli, S.; Vecchiocattivi, F. Ionization of ammonia molecules by collision with metastable neon atoms. Chem. Phys. Lett. 1999, 308, 71-77.

33. Brunetti, B.; Candori, P.; Falcinelli, S.; Vecchiocattivi, F.; Sassara, A.; Chergui, M. Dynamics of the Penning ionization of fullerene molecules by metastable Neon atoms. J. Phys. Chem. A 2000, $14,5942-5945$.

34. Brunetti, B.; Candori, P.; Falcinelli, S.; Kasai, T.; Ohoyama, H.; Vecchiocattivi, F. Velocity dependence of the ionization cross section of methyl chloride molecules ionized by metastable argon atoms. Phys. Chem. Chem. Phys. 2001, 3, 807-810.

35. Brunetti, B.; Candori, P.; Falcinelli, S.; Lescop, B.; Liuti, G.; Pirani, F.; Vecchiocattivi, F. Energy dependence of the Penning ionization electron spectrum of $\mathrm{Ne}^{*}\left({ }^{3} \mathrm{P}_{2,0}\right)+$ Kr. Eur. Phys. J. D 2006, $38,21-27$.

36. Kraft, T.; Bregel, T.; Ganz, J.; Harth, K.; Ruf, M.-W.; Hotop, H. Accurate comparison of Hel, NeI photoionization and $\mathrm{He}\left(2^{3,1} \mathrm{~S}\right), \mathrm{Ne}\left(3 s^{3} P_{2},{ }^{3} P_{0}\right)$ Penning ionization of argon atoms and dimers. Z. Phys. D 1988, 10, 473-481.

37. Kimura, K.; Katsumata, S.; Achiba, Y.; Yamazaky, T.; Iwata, S. Handbook of HeI Photoelectron Spectra of Fundamental Organic Molecules; Japan Scientific Societies Press: Tokyo, Japan, 1981.

38. West, W.P.; Cook, T.B.; Dunning, F.B.; Rundel, R.D.; Stebbings, R.F. Chemiionization involving rare gas metastable atoms. J. Chem. Phys. 1975, 63, 1237-1242. 
39. Arfa, M.B.; le Coz, G.; Sinou, G.; le Nadan, A.; Tuffin, F.; Tannous, C. Experimental study of the Penning ionization of the $\mathrm{H}_{2} \mathrm{O}$ molecule by $\mathrm{He}^{*}\left(2^{3} \mathrm{~S}, 2^{1} \mathrm{~S}\right)$ metastable atoms. J. Phys. B At. Mol. Opt. Phys. 1994, 27, 2541-2550.

40. Miller, W.H. Theory of Penning ionization. I. Atoms. J. Chem. Phys. 1970, 52, 3563-3571.

41. Hotop, H.; Niehaus, A. Reactions of excited atoms molecules with atoms and molecules. II. Energy analysis of penning electrons. Z. Phys. D 1969, 228, 68-88.

42. Falcinelli, S.; Rosi, M.; Candori, P.; Vecchiocattivi, F.; Bartocci, A.; Lombardi, A.; Lago, N.F.; Pirani, F. Modeling the intermolecular interactions and characterization of the dynamics of collisional autoionization processes. In ICCSA 2013, Part I, LNCS 7971 Computational Science and its Applications; Murgante, B., Misra, S., Carlini, M., Torre, C.M., Nguyen, H.Q., Taniar, D., Apduhan, B.O., Gervasi, O., Eds.; Springer-Verlag: Berlin Heidelberg, Germany, 2013; pp. 47-56.

43. Falcinelli, S.; Rosi, M.; Candori, P.; Vecchiocattivi, F.; Farrar, J.M.; Pirani, F.; Balucani, N.; Alagia, M.; Richter, R.; Stranges, S. Kinetic energy release in molecular dications fragmentation after VUV and EUV ionization and escape from planetary atmospheres. Planet. Space Sci. 2014, 99, 149-157.

(C) 2015 by the authors; licensee MDPI, Basel, Switzerland. This article is an open access article distributed under the terms and conditions of the Creative Commons Attribution license (http://creativecommons.org/licenses/by/4.0/). 